\title{
Thymic lymphomas in Wistar rats exposed to N-methyl-N-nitrosourea (MNU)
}

\author{
Carla Adriene da Silva Franchi, ${ }^{1}$ Maura Moscardi Bacchi, ${ }^{2}$ Carlos Roberto Padovani ${ }^{3}$ and João Lauro Viana de \\ Camargo ${ }^{1,2,4}$
}

${ }^{1}$ Center for Genotoxins and Carcinogens Evaluation (TOXICAN), ${ }^{2}$ Department of Pathology, Faculty of Medicine and ${ }^{3}$ Department of Biostatistics, Institute of BioSciences, UNESP, Botucatu, 18618-000, SP, Brasil

(Received October 21, 2002/Revised January 9, 2003/Accepted January 15, 2003)

The Brazilian Agency for the Environment (IBAMA) recently adopted an alternative medium-term multiple-organ assay system with the Wistar rat strain for detection of the carcinogenic potential of pesticides. Originally, this initiation-promotion protocol was established in Japan with the isogenic Fischer 344 male rat. Among the initiating agents used in that assay, N-methyl- $\mathrm{N}$ nitrosourea (MNU) rapidly induces malignant lymphoma and leukemia and early mortality of rats from different strains. This study was developed to evaluate whether the outbred Wistar rats are also similarly susceptible to MNU. Particularly, it aimed to evaluate the dose-response relationship and to register the MNUinduced pre-neoplasia and neoplasia that may develop in the lympho-hematopoietic system (LHS) of the Wistar rat within a medium-term period. Four groups of male Wistar rats were treated during 2 weeks with vehicle or with MNU (80, 160 or 240 $\mathrm{mg} / \mathrm{kg}$ body weight, i.p.). After sacrifice at the 12th and 20th weeks, the thymus, spleen, bone marrow, cervical and mesenteric lymph nodes and liver were collected for analysis. At the 20th week, LHS malignant tumors and benign vascular tumors occurred only in the high- and intermediate-dose MNU-treated animals. Four animals treated with $240 \mathrm{mg} / \mathrm{kg}$ developed diffuse thymic lymphomas; two others, treated respectively with 240 $\mathrm{mg} / \mathrm{kg}$ and $160 \mathrm{mg} / \mathrm{kg}$, developed spleen hemangiomas. The present observations indicate that the Wistar strain is as susceptible as other strains to the early development of MNU-induced LHS (pre)neoplasia. Therefore, this strain seems suitable to be used as test system in bioassay protocols that adopt MNU as an initiating agent for carcinogenesis. (Cancer Sci 2003; 94: 240-243)

$\mathrm{T}$ he standard experimental procedure for detection of the carcinogenic potential of chemicals is the long-term bioassay with rats and mice. ${ }^{1,2)}$ However, due to its operational complexity, long duration and high cost, several alternative protocols have been proposed. ${ }^{1,3)}$ Among these, a medium-term (26-weeks) multiple-organ bioassay was established with the male Fischer 344 rats by a group of researchers led by Nobuyuki Ito, at the Nagoya City University Medical School. ${ }^{4-6)}$ Based on the initiation-promotion concept of chemical carcinogenesis, that bioassay is also referred to as DMBDD bioassay, after the initials of the five genotoxic chemicals used to initiate the carcinogenesis process in multiple target organs: N-diethylnitrosamine (DEN), N-methyl-N-nitrosourea (MNU), N-butyl$\mathrm{N}$-(4-hydroxybutyl)nitrosamine (BBN), N,N'-dimethylhydrazine (DMH) and N-bis(2-hydroxypropyl)nitrosamine (DHPN). ${ }^{4-6}$ In Brazil, the Institute for the Environment and Natural Resources (IBAMA) adopted in 1996 a modified protocol of the DMBDD bioassay as a valid source of evidence of the carcinogenic potential of pesticides. ${ }^{7}$ This modified protocol uses Wistar rats of both sexes instead of the male Fischer 344 rat. Since then, our laboratory has conducted several studies to build up a catalog of the lesions induced by the initiating agents in the Wistar rat. 8 ,

Among the initiating agents used in the DMBDD bioassay, MNU has a broad spectrum of target organs, including particu- larly the lympho-hematopoietic system (LHS). ${ }^{10)}$ In fact, when provided at relatively high doses, MNU characteristically induces early and high incidence of leukemia and malignant lymphomas in young rats, ${ }^{10-12)}$ resulting in a high mortality rate of the animals and limiting the development of long-term experimental studies. In the present study the LHS was chosen for evaluation because it is an early target of MNU and its morphologic evaluation may provide rapid evidence of the carcinogenic influence of that agent in the Wistar strain.

In the original DMBDD bioassay with the Fischer 344 male rat, MNU is applied at a sub-carcinogenic dose level $(80 \mathrm{mg} /$ $\mathrm{kg}$ ). ${ }^{5,6)}$ The mortality rate and the spectrum of LHS (pre)neoplasias at a relatively low MNU dose level have not been established for the Wistar rat in medium-term observation. Therefore, a dose-response evaluation of MNU-dependent characteristic lesions - such as early LHS tumors - is a necessary step to better establish the DMBDD assay with the Wistar strain.

In this 20-week study we examined morphologically the LHS of male Wistar rats exposed to three different doses of MNU. Since the bone marrow, the lymph nodes, the spleen and the thymus should be considered as a single system, ${ }^{13)}$ we performed an integrated, simultaneous morphologic evaluation of these organs.

\section{Materials and Methods}

Animals. Eight-week-old male Wistar rats from a local strain were obtained from the Paraná Institute of Technology (TECPAR, Curitiba, Brazil) and housed five per polypropylene plastic cage with wood chips for bedding in an animal room with controlled conditions of temperature $\left(22 \pm 2^{\circ} \mathrm{C}\right)$, humidity $(55 \pm 10 \%)$ and lighting ( $12 \mathrm{~h} \mathrm{light/dark})$. They were fed $\mathrm{ad} l i$ bitum commercial chow (NUVILAB-CR1, NUVITAL, Paraná, Brazil) and tap water. The experiment started after an acclimation period of 4 weeks. The University Committee for Ethics in Animal Research approved the procedures adopted in this study (Protocol No. 119/00).

Chemical carcinogen. N-Methyl-N-nitrosourea (MNU, Sigma Chemical Co., St. Louis, MO, Catalog No. 684-93-5) was used to initiate the carcinogenesis process.

Experimental design. The experimental design is presented in Fig. 1. Male rats of similar body weights $(220-230 \mathrm{~g})$ at the beginning of the experiment were allocated to four experimental groups, one control (untreated) and three groups which received, during the first 2 weeks of the experiment, four i.p. injections of MNU (two injections/week) at the following doses: $20 \mathrm{mg} / \mathrm{kg}$ of body weight (total of $80 \mathrm{mg} / \mathrm{kg}$ ), $40 \mathrm{mg} / \mathrm{kg}$ (total of $160 \mathrm{mg} / \mathrm{kg}$ ) or $60 \mathrm{mg} / \mathrm{kg}$ (total of $240 \mathrm{mg} / \mathrm{kg}$ ). After carcinogen treatment, they were kept on basal diet and water $a d$ libitum until sacrifice at the 12th and 20th weeks of the experiment, when they were killed by exsanguination under ether an-

\footnotetext{
${ }^{4}$ To whom correspondence should be addressed. E-mail: decam@fmb.unesp.br
} 


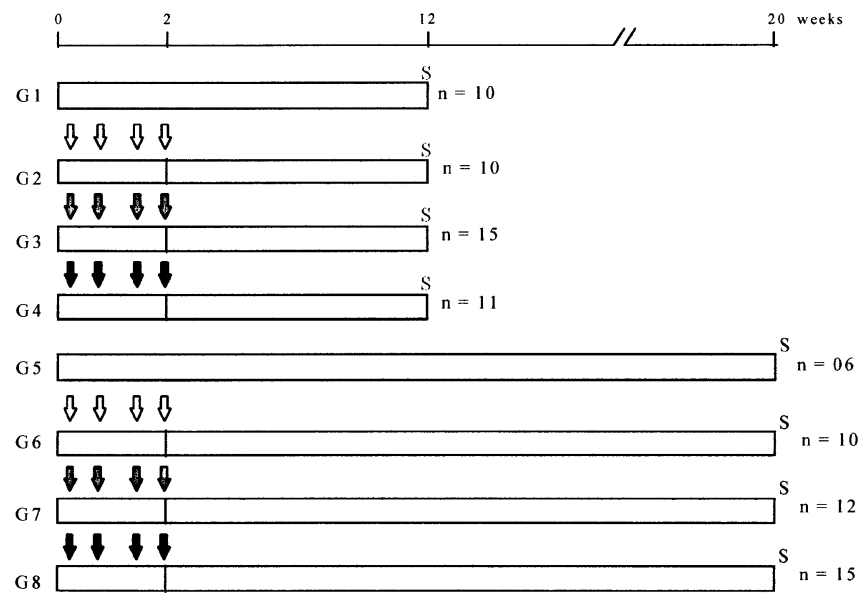

Fig. 1. Experimental design. $\mathrm{MNU}=\mathrm{N}-$ methyl-N-nitrosourea. $\Omega \mathrm{MNU}$ $80 \mathrm{mg} / \mathrm{kg}$ i.p. $(4 \times 20 \mathrm{mg}), \sqrt{\mathrm{MNU}} 160 \mathrm{mg} / \mathrm{kg}$ i.p. $(4 \times 40 \mathrm{mg}), \sqrt{\mathrm{MNU}}$ $240 \mathrm{mg} / \mathrm{kg}$ i.p. $(4 \times 60 \mathrm{mg}) . n$, effective number of animals; $S$, sacrifice.

esthesia. Complete gross examination was performed for detection of tumor masses. The thymus, spleen, bone marrow (right femur), lymph nodes (cervical and mesenteric) and liver were collected for histological analysis. The liver and spleen were weighed immediately after removed and blotted dry. The 20 th week of the study was established as the latest moment for observation, taking in consideration the information that MNU at $160 \mathrm{mg} / \mathrm{kg}$ of body weight i.p. induces leukemia and malignant lymphoma in 10-20\% of exposed male Fischer 344 rats before this time point. ${ }^{10,14)}$ Accordingly, the 12th week was proposed as a convenient point for detection of possible preneoplastic lesions.

Histological and immunohistochemical analysis. The liver, spleen, thymus, lymph nodes, the right femur and any tumor mass found were fixed in $10 \%$ buffered formalin during $48 \mathrm{~h}$. After fixation, the right femur was decalcified, washed in tap water and sectioned. Paraffin-embedded sections (5 $\mu \mathrm{m}$ thickness) were stained with hematoxylin and eosin $(\mathrm{H} \& \mathrm{E})$ for histological analysis. Sections of a lymphoma found in the mediastinum of one animal were submitted to immunohistochemical staining with anti-cytokeratin antibodies (M3515, DAKO Co., Carpinteria, CA) for identification of epithelial remnants within the tumoral mass to confirm the thymic origin of the neoplasia. Sections of the liver were also submitted to immunohistochemical detection of putative preneoplastic foci of hepatocytes that express the enzyme glutathione S-transferase, placental form (GST-P) with anti-GST-P antibodies (MBL, Nagoya). The immunohistochemical studies were performed using the avidin-biotin method. ${ }^{15)}$ The anti-cytokeratin and the anti-GST-P antibodies were used at the concentrations of 1:300 and 1:1000, respectively.

Hematological evaluation and bone marrow cytology. During necropsies, peripheral blood samples were collected in vacutainer tubes with 15\% EDTA and differentially quantified through a T890 Coulter counter for the following: leukocyte, erythrocyte and platelet counts, hematocrit, hemoglobin concentration, mean corpuscular volume, mean corpuscular hemoglobin and mean corpuscular hemoglobin concentration. Cytological smears of the left femur bone marrow were prepared immediately after necropsies and stained by Leishman's method. ${ }^{16)}$

Statistical analysis. Analysis of variance (ANOVA) was used to evaluate the differences among the body weights and the absolute and relative weights of liver and spleen of the groups treated with the four different doses of MNU. The differences of incidence of lesions among the groups were assessed by applying the Goodman test. ${ }^{17)}$ Differences were considered significant when $P<0.05$.

\section{Results}

Body weights. The lower $(80 \mathrm{mg} / \mathrm{kg})$ and intermediate $(160 \mathrm{mg} /$ $\mathrm{kg}$ ) MNU-dosed groups gained body weight progressively during the experiment, and at the end of the study (20th week) they did not differ significantly from the control group. At this time point, however, the highest dose group $(240 \mathrm{mg} / \mathrm{kg})$ presented a mean body weight significantly lower $(-17 \%)$ than the control.

Lympho-hematopoietic organs. At the 20th week, the mean relative spleen weight of the highest dose group was significantly increased $(+21 \%)$ when compared to the other groups. However, no conspicuous spleen histological alteration was apparent in these animals. An animal treated with $240 \mathrm{mg} / \mathrm{kg}$ presented a large mediastinal lymphoma, which diffusely infiltrated the thoracic wall and the diaphragm, involving the liver and the spleen. Under H\&E staining, this was a medium-sized cell type thymic lymphoma ${ }^{18)}$ composed predominantly of monotonous sheets of lymphoblastic cells and a few macrophages which gave the appearance, at low magnification, of a "starry sky" pattern (Fig. 2). The thymic origin of this lymphoma was confirmed by the demonstration of cytokeratin-positive probable remnants of the thymic Hassal's bodies within the tumor mass (Fig. 3). No other gross alteration of the thymus was found in any animal in the experiment.

Other malignant and benign tumors were found histologically in the LHS in the high- and intermediate-dose MNU-treated animals (Table 1). Three incipient thymic lymphomas occurred in the animals treated with $240 \mathrm{mg} / \mathrm{kg}$ of MNU; they were unilateral intralobular neoplasias that did not enlarge the organ (Fig. 4). Two animals, treated respectively with $240 \mathrm{mg} / \mathrm{kg}$ and 160 $\mathrm{mg} / \mathrm{kg}$, developed spleen hemangiomas and one animal treated with $160 \mathrm{mg} / \mathrm{kg}$ presented spleen angioectasias.

At both 12th and 20th weeks, the hematological parameters were within the range of reference values for control rats. ${ }^{19}$ Also, no animal in this study presented conspicuous histological alterations in the lymph nodes or in the bone marrow of the right femur. Accordingly, no alterations in the cytological pattern of the left femur bone marrow smears were verified in any group at the 12th and 20th weeks. The bone marrow smears showed intact and high cellularity of the granulocytic, erythro-

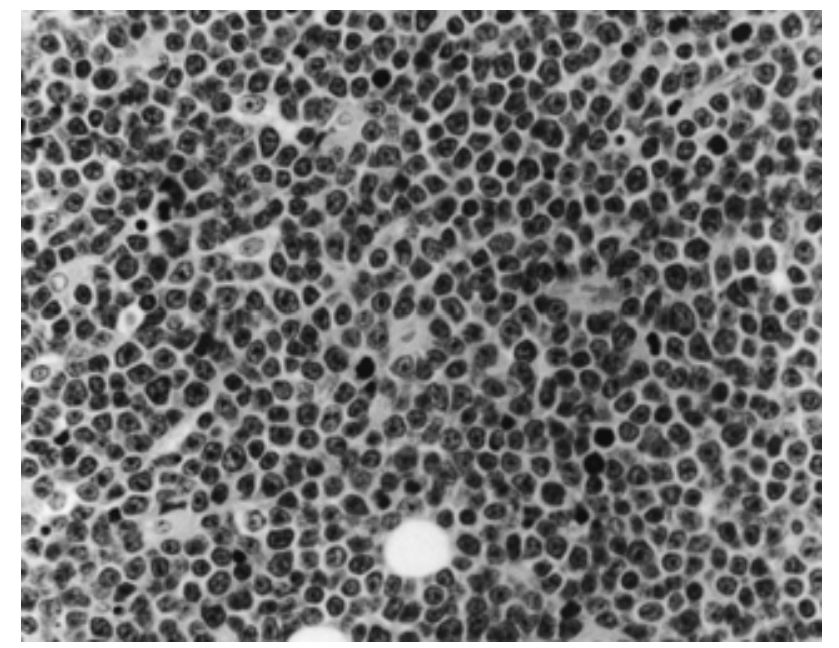

Fig. 2. Diffuse lymphoblastic thymic lymphoma (medium-sized cells type). (H\&E, 1000×) 


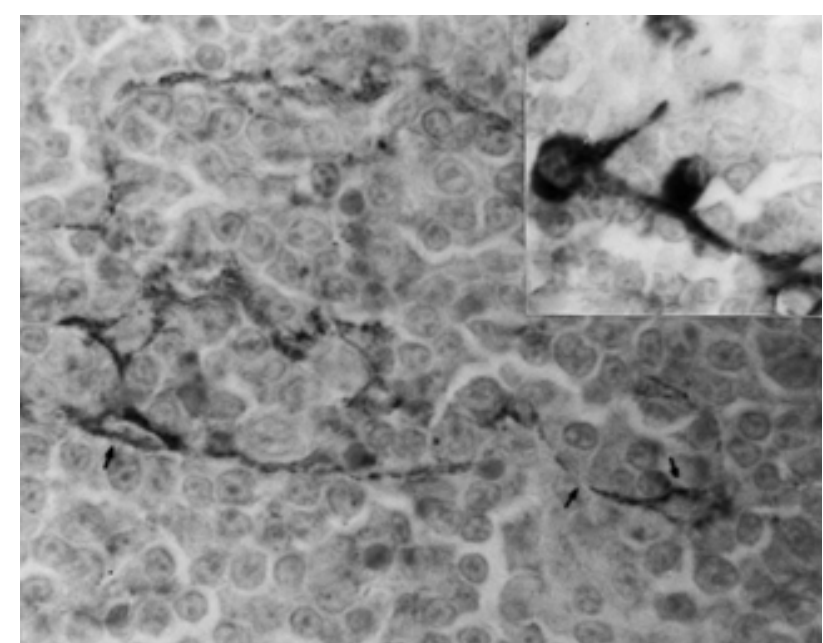

Fig. 3. Diffuse lymphoblastic thymic lymphoma-probable remnants of thymic Hassall's epithelial bodies within the lymphoma: cells and reticular structures positive for AE-1/AE3 cytokeratins. (Immunostaining by the avidin-biotin peroxidase method, $1000 \times$ )

Table 1. Incidences of (pre)neoplasia in the thymus and spleen of male Wistar rats at the end of the experiment (20th week)

\begin{tabular}{lcccc}
\hline Organ/lesion & \multicolumn{4}{c}{ Experimental groups } \\
\hline $\begin{array}{c}\text { Effective number } \\
\text { of animals }\end{array}$ & $\mathrm{G}_{0}$ & $\mathrm{G}_{80}$ & $\mathrm{G}_{160}$ & $\mathrm{G}_{240}$ \\
\cline { 2 - 5 } & 6 & 10 & $10(\%)$ & $15(\%)$ \\
\hline $\begin{array}{c}\text { Thymus } \\
\text { Lymphoma }\end{array}$ & 0 & 0 & 0 & $4(27)$ \\
$\begin{array}{c}\text { Spleen } \\
\text { Angiectasia }\end{array}$ & 0 & 0 & 0 & $1(7)$ \\
$\quad$ Hemangioma & 0 & 0 & $1(10)$ & $1(7)$ \\
Liver & 0 & 0 & 0 & $15(100)^{3)}$ \\
$\quad$ GST-P+ foci ${ }^{2)}$ & 0 & &
\end{tabular}

1) $G_{0}, G_{80}, G_{160}$ and $G_{240}=$ control and MNU-treated animals with 80 , 160 and $240 \mathrm{mg} / \mathrm{kg}$, respectively.

2) GST-P+ foci=foci of altered hepatocytes expressing the enzyme glutathione S-transferase, placental form.

3) A few foci with 3-4 positive hepatocytes each.

cytic and megakaryocytic cell lineages irrespective of whether the animal was treated with MNU or not.

Liver. At the 20th week, the mean absolute and relative liver weights did not differ among the groups, irrespective of MNU treatment. Although no conspicuous histological alterations were seen in the liver of any group, every animal exposed to $240 \mathrm{mg} / \mathrm{kg}$ of MNU showed a few preneoplastic GST-P-positive minifoci in the liver, with 3-4 hepatocytes each.

\section{Discussion}

Putative MNU-related effects were verified only at the 20th week of the study in the animals exposed to the highest dose $(240 \mathrm{mg} / \mathrm{kg}$ ), as shown by significantly diminished mean body weight and tumor development in the thymus and spleen. The 12th week seemed to be too early for detection of MNU-related LHS alterations; preneoplastic incipient lesions were registered only at the 20th week, synchronously with well-established thymus and spleen neoplasia. As will be discussed below, these early lesions corresponded to intra-lobular thymic lymphoma, spleen angioectasias and GST- $\mathrm{P}^{+}$-altered foci of hepatocytes, which should be considered as putative markers of the MNUinitiated carcinogenesis in the Wistar rat.

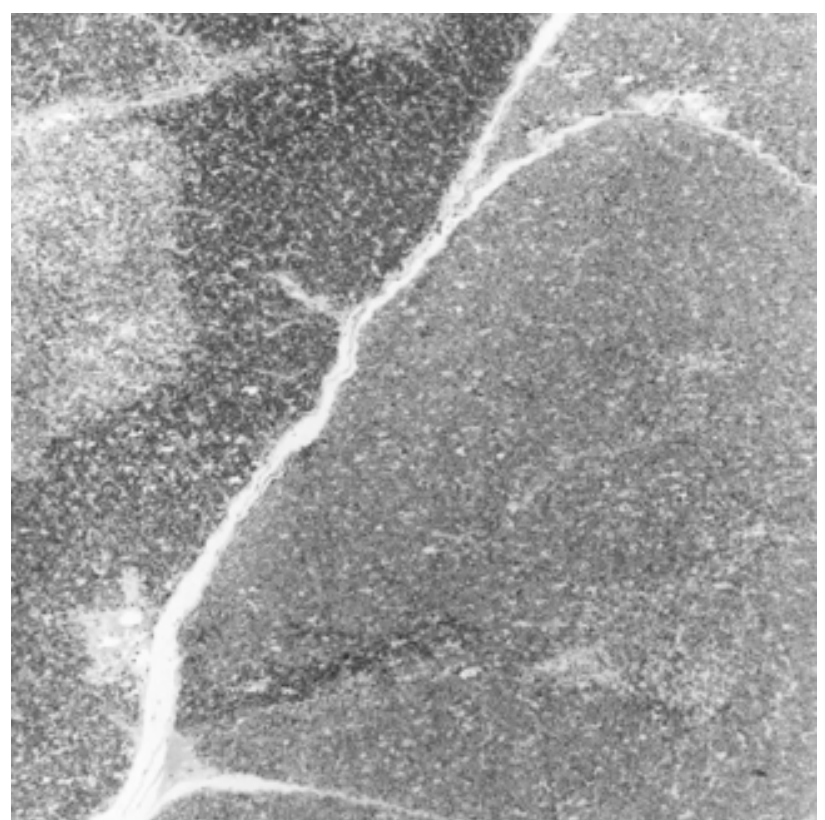

Fig. 4. Thymus lobule (at right) altered by diffuse lymphoma growth. The lobule at the left retains the normal thymic structure. (H\&E, 132×)

The thymic lymphomas found in this study at a $27 \%$ incidence should be assumed as dependent on MNU, because these tumors did not occur in control rats or in intermediate- and lower-dose treated animals, and the rats that developed tumors were younger than 28 weeks of age, when spontaneous tumors are not common in this species. ${ }^{20)}$ In one animal the neoplasia was very aggressive and infiltrated thoracic and abdominal organs, but in three other rats, the microscopically diagnosed thymic lymphomas showed only intra-lobar involvement, i.e., they were in a very early stage of development. These neoplastic growths were lymphoblastic lymphomas, like the early MNUinduced thymic lymphomas described in other rat strains. ${ }^{18,21)}$

The incidence of thymic lymphomas induced by nitrosoureas in rats has been reported as variable, depending on the strain and on the duration of the study. Fischer 344 rats treated with a total dose of $240 \mathrm{mg} / \mathrm{kg}$ of MNU - the same as the highest dose of the present study - for 6 weeks and sacrificed 18 weeks later presented a $97 \%$ incidence of thymic lymphomas. ${ }^{12)}$ Sprague-Dawley animals treated intra-gastrically with $360 \mathrm{mg} / \mathrm{kg}$ of MNU showed a $100 \%$ incidence of thymic lymphoma at the 15th week. ${ }^{21)}$ After treatment with $400 \mu \mathrm{g} / \mathrm{ml}$ of propylnitrosourea (PNU) dissolved in drinking water for 28 weeks, the incidence of thymic lymphomas was different among Fischer 344 (incidence of 98\%), Wistar/Furth (71\%), Sprague-Dawley (29\%), ACI/Ms (23\%), Donryu (24\%) and Long-Evans (10\%) rats. ${ }^{22)}$ Therefore, although relatively low, the $27 \%$ incidence of thymic lymphoma observed in the highest-dose group at the 18th week after the end of the MNU-treatment points to a medium-term carcinogenic influence of that chemical in the Wistar strain.

MNU acts as a direct carcinogenic alkylating agent, and persistent $\mathrm{O}^{6}$-methylguanine adducts have been proposed to be the critical lesion in a variety of MNU-induced tumors. Tissues more susceptible to the carcinogenic effect of nitrosoureas have 3 to 18 times less activity of the DNA repair enzyme alkyltransferase than tissues less susceptible to these agents. ${ }^{23-25}$ ) When transgenic mice express the human $\mathrm{O}^{6}$-alkylguanineDNA alkyltransferase in the thymus they present a reduced incidence (from $58 \%$ to $4 \%$ ) of thymic lymphomas after MNU exposure, that is, the thymus is protected from developing neo- 
plasia. $^{23)}$ Therefore, the susceptibility of the rodent thymus to develop earlier and more aggressive MNU-dependent tumors seems to depend particularly on its limited capability for DNA repair through the enzyme $\mathrm{O}^{6}$-alkylguanine-DNA alkyltransferase. ${ }^{23,26)}$

Since MNU has a broad spectrum of target organs, the possibility exists that if the experiment had been extended in time, tumors would have developed in other tissues. ${ }^{10,26)}$ The present study, however, focused only on LHS tumors because they could be used as early markers of the carcinogenic influence of MNU on the Wistar strain. The development of putatively preneoplastic liver GST-P ${ }^{+}$foci of hepatocytes was also evaluated, because this has been an important parameter in the rat alternative medium-term bioassays for carcinogenesis. ${ }^{5,27)}$ In the present case, GST-P ${ }^{+}$foci were associated only with the highest dose of MNU, being rare and very small, in concordance with the weak MNU initiation activity in the liver. ${ }^{28)}$

The low total incidence $(2 / 25,8 \%)$ of spleen hemangiomas in the intermediate and high-dose treated groups makes it difficult to establish a causal relationship of these benign lesions

1. Bannasch P, Griesemer RA. Long-term assays for carcinogenicity in animals. In: Montesano R, Bartsch H, Vainio H, Wilbourn J, Yamasaki H, editors. Long-term and short-term assays for carcinogens: a critical appraisal. IARC Sci Publ 1986; 83: 13-83.

2. Chhabra RS, Huff JE, Schwetz BS, Selkirk J. An overview of prechronic and chronic toxicity/carcinogenicity experimental study designs and criteria used by the National Toxicology Program. Environ Health Perspect 1990; 86: 313-21.

3. Boorman GA, Maronpot RR, Eustis SL. Rodent carcinogenesis bioassay: past, present and future. Toxicol Pathol 1994; 22: 105-11.

4. Ito N, Imaida K, Tsuda H, Shibata M, Aoki T, de Camargo JLV, Fukushima S. Wide-spectrum initiation models: possible applications to medium-term multiple organ bioassays for carcinogenesis modifiers. Jpn J Cancer Res 1988; 79: 413-7.

5. Shirai T, Hirose M, Ito N. Medium-term bioassays in rats for rapid detection of the carcinogenic potential of chemicals. In: McGregor DB, Rice JM, Venitt S, editors. The use of short- and medium-term tests for carcinogens and data on genetic effects in carcinogenic hazard evaluation. IARC Sci Publ 1999; 146: $251-72$

6. Hagiwara A, Tanaka H, Imaida K, Tamano S, Fukushima S, Ito N. Correlation between medium-term multi-organ carcinogenesis bioassay data and long-term observation results in rats. Jpn J Cancer Res 1993; 84: 237-45.

7. Brazilian Institute of Environmental and Renewable Natural Resources (IBAMA). Normative Act No.84, October 15 (1996) (in Portuguese).

8. Spinardi ALT, Kaneno R, Rodrigues MAM, Salvadori DMF, Rocha NS, Barbisan LF, Ribeiro LR, de Camargo JLV. Natural killer activity in a medium-term multi-organ bioassay for carcinogenesis. Jpn J Cancer Res 1999; 90: $101-7$.

9. Moreira ELT, de Camargo JLV, Rodrigues MAM., Barbisan LF, Salvadori DMF. Dose- and sex-related carcinogenesis by N-bis(2-hydroxypropyl)nitrosamine in Wistar rats. Jpn J Cancer Res 2000; 91: 368-74.

10. Uwagawa $\mathrm{S}$, Tsuda $\mathrm{H}$, Inoue $\mathrm{T}$, Tagawa $\mathrm{Y}$, Aoki T, Kagawa M, Ogiso T, Ito N. Enhancing potencial of 6 different carcinogens on multi-organ tumorigenesis after initial treatment with N-methyl-N-nitrosourea. Jpn J Cancer Res 1991; 82: 1397-405.

11. Tsuda H, Fukushima S, Imaida K, Kurata Y, Ito N. Organ specific promoting effect of phenobarbital and saccharin in induction of thyroid, liver and urinary bladder tumors in rats after initiation with $\mathrm{N}$-nitrosomethylurea. Cancer Res 1983; 43: 3292-6.

12. Mizoguchi M, Naito H, Kurata Y, Shibata M-A, Tsuda H, Wild CP, Montesano R, Fukushima S. Influence of aging on multi-organ carcinogenesis in rats induced by N-methyl-N-nitrosourea. Jpn J Cancer Res 1993; 84: 139-46.

13. Kociba RJ, Kociba GJ. Assessment of toxicologic effects upon bone marrow and related tissues. In: Jones TC, Ward JM, Mohr U, Hunt RD, editors. Monographs on the pathology of laboratory animals (hemopoietic system). Berlin-Heidelberg: Springer-Verlag; 1990. p.79-87.

14. Ito N, Shirai T, Hasegawa R. Medium-term bioassays for carcinogens. In: with MNU treatment. However, since spleen hemangiomas occurred only in MNU-treated animals and are reported to be of very rare occurrence in young rats, ${ }^{29)}$ it seems likely that they were also dependent on MNU exposure. The finding of angioectasia in the spleen of another animal also exposed to the intermediate dose of MNU supports the possibility that the spleen vessels are also a target of the carcinogen toxicity. In this context, it can be assumed that spleen vascular ectasia is a preneoplastic lesion of hemangiomas, as proposed by others. ${ }^{30)}$

The rapid development of thymus and spleen (pre)neoplasia after exposure to a relatively high dose level of MNU indicates that the outbred Wistar male rat is as susceptible as other rat strains to the carcinogenic influence of that carcinogen, developing marker lesions in the lympho-hematopoietic system that can be used as end-points in alternative carcinogenesis protocols.

The Fundação de Amparo à Pesquisa do Estado de São Paulo (FAPESP, No. 98/03035-8) and the Conselho Nacional de Pesquisas (CNPq, No. 300705/81-6) supported this study.

Vainio H, Magee PN, McGregor DB, McMichael AJ, editors. Mechanisms of carcinogenesis in risk identification. Lyon: International Agency for Research on Cancer (IARC); 1992. p. 353-88.

15. Hsu SM, Raine L, Fanger N. Use of avidin-biotin-peroxidase complex (ABC) and unlabeled antibody (PAP) procedures. J Histochem Cytochem 1981; 29: $577-80$.

16. Luna LG. Histopathologic methods and color atlas of special stains and tissues artifacts. Washington: American Histolabs; 1992. p. 275-6.

17. Goodman LA. On simultaneous confidence intervals for multinomial proportions. Technometrics 1965; 7: 247-54.

18. Ogiu T. T-Cell lymphoma, thymic origin, rat. In: Jones TC, Ward JM, Mohr $\mathrm{U}$, Hunt RD, editors. Monographs on pathology of laboratory animals (Hemopoietic System). Berlin-Heidelberg: Springer-Verlag; 1990. p. 286-92.

19. Harkness JE, Wagner JE. The biology and medicine of rabbits and rodents. Media: Williams \& Wilkins; 1995. p. 95.

20. Hayashi S, Nonoyama T, Miyajima H. Spontaneous non-thymic cell lymphomas in young Wistar rats. Vet Pathol 1989; 26: 326-32.

21. Koestner AW, Ruecker FA, Koestner A. Morphology and pathogenesis of tumors of the thymus and stomach in Sprague-Dawley rats following intragastric administration of methylnitrosourea (MNU). Int J Cancer 1977; 20: $418-26$.

22. Shisa H, Hiai H. Genetically determined susceptibility of Fischer 344 rats to propylnitrosourea-induced thymic lymphomas. Cancer Res 1985; 45: 14837.

23. Dumenco LL, Allay E, Norton K, Gerson SL. The prevention of thymic lymphomas in transgenic mice by human $O^{6}$-alkylguanine-DNA alkyltransferase. Science 1993; 59: 219-22.

24. Gerson SL, Miller K, Berger NA. $\mathrm{O}^{6}$ alkylguanine-DNA alkyltransferase activity in human myeloid cells. J Clin Invest 1985; 76: 2106-14.

25. Fong LY, Jensen DE, Magee PN. DNA methyl-adduct dosimetry and O6alkylguanine-DNA alkyl transferase activity determinations in rat mammary carcinogenesis by procarbazine and N-methylnitrosourea. Carcinogenesis 1990; 11: 411-7.

26. Swenberg JA, Koestner A, Wechsler W, Brunden MN, Abe H. Differential oncogenic effects of methylnitrosourea. J Natl Cancer Inst 1975; 54: 86-95.

27. Moore MA, Tsuda H, Tamano S, Hagiwara A, Imaida K, Shirai T, Ito, N. Marriage of a medium-term liver model to surrogate markers - a practical approach for risk and benefit assessment. Toxicol Pathol 1999; 27: 237-42.

28. Yoshida Y, Tatematsu M, Takaba K, Iwasaki S, Ito, N. Target organ specificity of cell proliferation induced by various carcinogens. Toxicol Pathol 1993; 21: $436-42$

29. Losco P. Normal development, growth and aging of the spleen. In: Mohr U, Dungworth DL, Capen CC, editors. Pathobiology of the aging rat. Washington: International Life Sciences Institute; 1992. p. 75-93.

30. Ward JM. Classification of reactive lesions, spleen. In: Jones TC, Ward JM, Mohr U, Hunt RD, editors. Monographs on pathology of laboratory animals (Hemopoietic System). Berlin-Heidelberg: Springer-Verlag; 1990. p. 220-6. 